\title{
Difficulties in diagnosing intrinsic spinal cord tumours
}

\author{
A P J Parker, R O Robinson, P Bullock
}

Thirteen children with intrinsic spinal cord tumours were seen between 1984 and 1995. In only one was this the presumptive diagnosis at referral, despite a high incidence of characteristic features. Eight had presented to their local paediatrician, four to local orthopaedic teams, and one to a general surgeon. Eleven had back pain. Eleven had either spinal curvature or change in gait. The interval between onset of symptoms and diagnosis ranged from one week to six years, with a mean of 17.5 months. In nine children symptoms had been present for four or more months. In nine, unrewarding investigations had been carried out. This paper highlights typical presenting features of these tumours and how earlier diagnosis can be achieved. (Arch Dis Child 1996;75:204-207)

Keywords: spinal cord, tumour, back pain.

Children are rarely referred to us with a diagnosis of intrinsic spinal cord tumours. This is partly due to their low incidence: two cases per million children per year, ${ }^{12}$ which implies that general practitioners are unlikely to see a child with a cord tumour, and district general hospital consultants only rarely. Initial manifestations vary but there are characteristic features which should bring the diagnosis to mind. Failure to recognise these may lead to delay and unnecessary or ill directed investigations.

We review our experience of children presenting with intrinsic cord tumours against the background of the duration of symptoms.

Newcomen Centre, Guy's Hospital, London SE1 A P J Parker R O Robinson

Department of Neurosurgery, Maudsley Hospital, London SE5

P Bullock

Correspondence to: Dr A Parker, Newcomen Centre, Guy's Hospital, London SE1 7RT.

Accepted 7 June 1996 We reviewed medical notes and radiological investigations of children with spinal cord tumours presenting to Guy's and the Maudsley Hospital during the 11 year period from 1984 to 1995 . An additional check was made from the radiotherapy records which are kept separately. The site and type of tumour was identified by magnetic resonance imaging (MRI). The pathological diagnosis was made on tissue obtained by biopsy or resection in all cases.

\section{Results}

Thirteen children (six boys and seven girls ) were identified, with a mean age at presenta- tion of 5.4 years (range 8 months to 11 years). Six had astrocytomas, three had ependymomas, and there was one each with primitive neuroectodermal tumour, hamartoma, neuroenteric cyst, and ganglioglioma. Five were confined to the cervical region, five thoracic, and one lumbar. Two were more extensive being cervicothoracic or thoracolumbar.

Eight $(62 \%)$ were referred by their general practitioner to the local paediatric team, four ( $31 \%)$ to the orthopaedic team, and one (7\%) to a general surgeon.

At presentation to the regional neurology centre, 10 children had a history of spinal pain: two of the exceptions were 7 and 12 months old respectively at presentation. Seven had spinal curvature, and two had reduction in spinal movement with no curvature. Six had change in gait, one (aged 12 months) had reduction in leg movement (see fig 1). Two were paraplegic by the time of presentation. On admission, all the children had at least one neurological sign relating to the site of their tumour.

The spinal curvature was due either to kyphoscoliosis (5), torticollis (3), or both. In all three children with torticollis the tumour involved the cervical cord. The site varied in the cases with kyphoscoliosis. Less common presenting features including congenital dislocation of the hip, recurrent pneumonia, and acute abdomen are detailed in the illustrated case histories.

Bladder and bowel habit was recorded in $\mathbf{1 2}$ of the children. Of these, six had been constipated - one was admitted for this -and the remaining children had normal bowel function. Five children had urinary symptoms: two a neuropathic bladder, two were incontinent, and one had nocturnal frequency of micturition.

Power, tone, reflexes, and gait were recorded 
Age, site, symptoms, time to diagnosis, diagnosis and presentation of 13 children with spinal cord tumours

\begin{tabular}{|c|c|c|c|c|c|c|}
\hline & $\begin{array}{l}\text { Age at onset } \\
\text { of symptoms }\end{array}$ & Symptoms & $\begin{array}{l}\text { Time from initial } \\
\text { presentation to } \\
\text { diagnosis }\end{array}$ & Initial diagnosis & Findings on presentation to Guy's & Site \\
\hline $\begin{array}{l}\text { Case } 1 \\
\text { Case } 2\end{array}$ & $\begin{array}{l}10 \text { months } \\
5 \text { years }\end{array}$ & $\begin{array}{l}\text { Axillary/back pain, hunching } \\
\text { Torticollis/kyphosis, back pain, } \\
\text { stiffness in legs }\end{array}$ & $\begin{array}{l}18 \text { months } \\
6 \text { months }\end{array}$ & $\begin{array}{l}\text { Migraine } \\
\text { Muscle spasm }\end{array}$ & $\begin{array}{l}\text { Abnormal gait, scoliosis } \\
\text { Torticollis, kyphosis, hyperreflexia } \\
\text { and raised tone }\end{array}$ & $\begin{array}{l}\text { C } \\
\text { C }\end{array}$ \\
\hline Case 3 & 4 years & Limb weakness, back pain & 1 week & Spinal tumour & $\begin{array}{l}\text { Brisk leg reflexes, decreased leg } \\
\text { sensation }\end{array}$ & C \\
\hline Case 4 & 10 years & Neck pain, weakness, torticollis & 4 months & Trauma & $\begin{array}{l}\text { Decreased power and reflexes in } \\
\text { right arm }\end{array}$ & C \\
\hline Case 5 & Birth & Hydrocephalus & 3.5 years & Hydrocephalus & $\begin{array}{l}\text { Scoliosis, increased arm reflexes, } \\
\text { decreased leg reflexes }\end{array}$ & C \\
\hline Case 6 & 3 years & $\begin{array}{l}\text { Torticollis, recurrent chest } \\
\text { infections, back pain }\end{array}$ & 3 weeks & $\begin{array}{l}\text { Atypical pneumonia, Sandifer's } \\
\text { syndrome }\end{array}$ & $\begin{array}{l}\text { Bulbar signs with abnormal reflexes } \\
\text { in arms and legs }\end{array}$ & CT \\
\hline Case 7 & 6 years & Lower back pain & 18 months & Spinal lesion & Reduced spinal flexion & $\mathrm{T}$ \\
\hline Case 8 & 12 months & Neck stiffness, fever & 1 week & Spinal lesion & $\begin{array}{l}\text { Right sided increase in tone and } \\
\text { reflexes }\end{array}$ & $\mathbf{T}$ \\
\hline $\begin{array}{l}\text { Case } 9 \\
\text { Case } 10 \\
\text { Case } 11\end{array}$ & $\begin{array}{l}3 \text { years } \\
7 \text { months } \\
5 \text { years }\end{array}$ & $\begin{array}{l}\text { Back pain and gradual paraparesis } \\
\text { Paralysis of lower limbs } \\
\text { Abdominal/back pain, constipation }\end{array}$ & $\begin{array}{l}3 \text { weeks } \\
6 \text { weeks } \\
2 \text { weeks }\end{array}$ & $\begin{array}{l}\text { Muscle pain and anxiety } \\
\text { None made } \\
\text { Acute abdomen }\end{array}$ & $\begin{array}{l}\text { Quadriparesis } \\
\text { Quadriparesis } \\
\text { Reduced power and reflexes in right } \\
\text { arm }\end{array}$ & $\begin{array}{l}\mathrm{T} \\
\mathrm{TL} \\
\mathrm{T}\end{array}$ \\
\hline $\begin{array}{l}\text { Case } 12 \\
\text { Case } 13\end{array}$ & $\begin{array}{l}3 \text { years } \\
\text { Birth }\end{array}$ & $\begin{array}{l}\text { Back pain, spinal curvature } \\
\text { Dislocated hip, back pain }\end{array}$ & $\begin{array}{l}6 \text { weeks } \\
6 \text { years }\end{array}$ & $\begin{array}{l}\text { No abnormality } \\
\text { Congenital dislocation of hip }\end{array}$ & $\begin{array}{l}\text { Kyphoscoliosis } \\
\text { Absent left leg reflexes }\end{array}$ & $\mathbf{L}$ \\
\hline
\end{tabular}

$\mathrm{C}=$ cervical $\mathrm{CT}=$ cervicothoracic $\mathrm{T}=$ thoracic $\mathrm{TL}=$ thoracolumbar $\mathrm{L}=$ lumbar.

fore present a particular diagnostic challenge. The average interval between presentation to the district paediatric service and referral to the regional paediatric neurology unit in the whole group was 12 months (range one week to six years). If cases 5 and 10 are excluded the average is still 3.3 months (see table 1 ).

MRI revealed the cord abnormality in all 13 children. Six had spinal $x$ rays taken at the referring hospital within six weeks before the MRI scan, only one of which was reported as abnormal.

\section{ILLUSTRATIVE CASE HISTORIES}

Case 6

This girl was investigated for a six month history of epigastric discomfort, back pain, and persistent head tilt. A presumptive diagnosis of Sandifer's syndrome ${ }^{3}$ was made. She subsequently developed a series of progressively worse chest infections, for the last of which she was admitted. During this time her voice became nasal and she developed dysphagia.

She had already been noted to have situs inversus and the possibility of Kartagener's syndrome was raised to explain the repeated chest infections.

Over the succeeding few weeks she remained ventilator dependent. A diagnosis of atypical pneumonia was made. Vegetable fibres were found on lung biopsy. After reintubation, her inability to swallow, reduced arm reflexes, brisk reflexes in the lower limbs, sustained clonus in the right ankle, absent abdominal reflexes and up going plantar responses were noted.

MRI revealed a cystic tumour from the medulla to T12. Biopsy during surgical debulking confirmed the tumour to be an ependymoma for which she received radiotherapy. Four years later she is back at school with a scoliosis but no abnormality of gait, bladder, or bowels.

Case 11

This boy presented aged 5 years to a district general hospital with a 10 day history of abdominal pain associated with backache. He had been seen by his general practitioner who had noted scoliosis and constipation. He was admitted under the surgical team. He was initially managed with analgesia alone, but an exploratory laparotomy was performed several days later when a diagnosis of pseudoobstruction was made.

He initially recovered but continued to have back and sacral pain. Five days later, weakness of the right leg prompted referral. MRI revealed a spinal cord tumour, subsequently shown to be a thoracic astrocytoma. This was resected and he is now mobile but has a residual weakness of his right leg.

\section{Case 13}

This boy was noted to have bilateral postural talipes equinovarus at birth. He walked at 2 years with a rolling gait, tending to invert his left foot. At the age of 4 he developed a limp and was referred to an orthopaedic team. Reduced hip and knee flexion with shortening of the right leg were noted. A diagnosis of congenital dislocation of the hip was made and he underwent an open reduction. At the time of surgery, no abnormality of the joint was found despite the dislocation.

Two weeks later he complained of sacral pain, and $x$ ray showed that the hip had redislocated. On review, the paediatric team noted clonus of the left ankle with an equivocal plantar response and altered bowel habit. MRI revealed an intramedullary spinal tumour from T9-T12. He has had radiotherapy and two debulking procedures, when histological examination revealed a grade II astrocytoma. He walks, aided by a crutch, with reduced power in his left leg.

\section{Discussion}

Intraspinal tumours in children have been reviewed elsewhere. ${ }^{45}$ In this paper we highlight problems experienced in diagnosis despite typical features on presentation. There was some delay in all patients before referral, the majority waiting more than three months. In only three out of 13 was a spinal tumour mentioned as a possibility in the referral letter. 
Our group was typical in terms of site, age, and sex. ${ }^{45}$ Forty five per cent of the tumours had a rostral position. All children were aged less than 11 years, slightly younger on average age than in other reports. ${ }^{5}$ The sex ratio was almost even - six female to seven male, similar to the series of Dincer $e t a l .^{6}$

The children in our series had long delays between onset of symptoms and diagnosis, with two taking several years and the remainder averaging almost 10 months. Previous reports have shown a delay between onset of symptoms and diagnosis from several months to several years, ${ }^{46}$ 7-9 with misdiagnosis in $30-70 \%$ of cases. $^{81011}$ The delay between presentation and diagnosis was similar to these series, taking many months in most cases. Despite the advent of MRI and other neuroimaging techniques, there has been little reduction in the time to diagnosis.

The commonest complaint was of chronic back pain. Dincer et al reported pain in $57 \%$ of their series and $85 \%$ had weakness of limbs or an abnormal gait on presentation. ${ }^{6}$ Back pain was reported by Cole in $40 \%$ of her series. ${ }^{12}$ Seventy seven per cent of the children in our series had chronic back pain. Two of the remaining three were very young, so this may not have been apparent. Back pain is uncommon in children and should always raise the suspicion of serious disease. ${ }^{13}$

The pain is commonly dull, worse at night, and may radiate into the neck (case 8 ), to specific dermatomes (case 1), or into the abdomen (case 11). Initially, tumour expansion causes dural distension, producing pain that is exacerbated by coughing or sneezing and which may be difficult for young children to describe. It is normally worst around the site of the tumour and may radiate into adjacent dermatomes. It is often possible to elicit the pain with pressure on the appropriate vertebrae. Later, pressure by the tumour on the nerve roots themselves produces more localised, radicular pain. Occasionally, pain radiates diffusely down a limb or part of the trunk: possible explanations for this have included irritation of paravertebral nervous plexuses and infiltration of spinothalamic tracts. ${ }^{714}$ Only $20 \%$ of intraspinal tumours will cause pain that can be localised to a specific dermatome. Matson and Tachdjian's series included five patients in whom appendicectomy had been performed. ${ }^{11}$ The management of case 11 highlights the problems in diagnosing tumours presenting with abdominal symptoms.

Torticollis, particularly if painful, should always be considered pathological. If there are no inflamed lymph nodes causing sternocleidomastoid muscular spasm, a tumour of the spinal cord or posterior fossa should be considered. ${ }^{15}$ In all patients with torticollis there was involvement of the cervical cord. Of note was case 4, where torticollis followed a minor injury on a 'bouncy castle'. As a result of the history of trauma further investigations were delayed.

Change in gait or kyphoscoliosis had occurred in all the children by the time of diagnosis, and kyphoscoliosis developed as the initial symptom in seven. Change in gait is due to reduction in power or change in tone from intrinsic cord involvement or, alternatively, from the back pain produced by dural extension. When associated with a spinal deformity the likelihood of an intrinsic cord lesion must arise. Although scoliosis is not uncommon, particularly in adolescents, it should be viewed with suspicion if pain coexists. There was no association between site of tumour and site of kyphoscoliosis. Thus, of the 13 children, all but two had at least two out of the three cardinal features of intrinsic spinal cord tumours: back pain, change in gait, and alteration in spinal movement or curvature (fig 1).

Loss of power in a myotomal distribution is rare, except as a late finding. Two of the children in our series had progressed as far as quadriparesis before referral, only one of whom improved marginally even after surgery, radiotherapy, and chemotherapy.

Loss of sensation tends to occur much later, rarely producing a sensory level, in contrast to transverse myelitis. ${ }^{512}$

Hydrocephalus is a well recognised feature of spinal tumours. Cervicomedullary expansion will impede cerebrospinal fluid circulation, as will subarachnoid seeding. Hydrocephalus in distal cord tumours may be caused by the raised protein content of the cerebrospinal fluid.

Anal sphincter disturbance is normally a very late finding and occurs more commonly in tumours of the conus ${ }^{4-6}{ }^{13}$; other investigators have quoted an incidence of around $10 \% .{ }^{6}{ }^{10}$ The one child in this series who became incontinent of faeces had a tumour of the conus. Constipation, often considered trivial by parents and clinicians, was far more common (45\%) than incontinence in our series, occurring before any other signs or symptoms in $50 \%$ of these children.

Urinary symptoms, like bowel symptoms, also occurred late, although delay in becoming dry was reported in the review by Cole. ${ }^{12}$ The findings were not dramatic: of the six children with urinary symptoms at referral two required catheterisation; the remaining four had problems varying from mild dribbling on exertion to enuresis. These four children became conti-

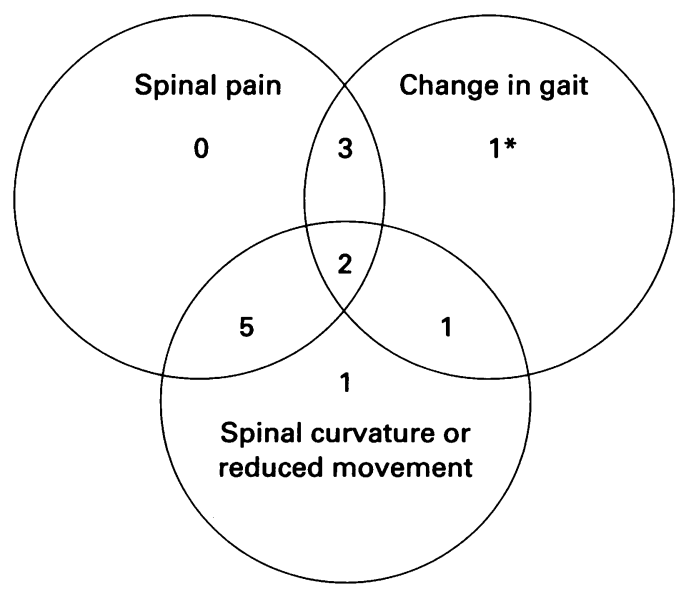

Figure 1 Venn diagram of signs and symptoms at presentation. Asterisk refers to 12 month old child unable to walk independently but reduction in leg movement. 
nent of urine after surgery. Loss of bladder control was not associated with the site of tumour and can occur with tumours up to cervical level.

Other presentations included congenital dislocation of the hip (case 13), which has not previously been described as secondary to a spinal tumour. Dislocation was thought to be due to loss of neuromuscular control in utero. In another patient, repeated chest infections, ultimately requiring treatment in an intensive care unit, were thought to be secondary to compromise of respiratory muscles and repeated aspiration (case 6).

Of the 13 children in our study, 10 are still alive. Eight have a static neurological deficit; six of these can walk but with an abnormal gait. The remaining two have normal gait but have spinal curvature. Spinal $x$ rays rarely reveal a spinal tumour, only one in our series being abnormal. Diagnosis by MRI is both quick and accurate. Intrinsic spinal cord tumours normally have low grade histological appearances. Improvements in surgery, radiotherapy, and chemotherapy have led to four year event-free survival, that is, with no further clinical deterioration, in $80-90 \%$ of this group. Ependymomas have an excellent prognosis, with $100 \%$ survival if treated early. ${ }^{5}{ }^{16}$ Outlook is still poor in children with high grade tumours.

Despite the advent of MRI, there has been little change in the time to diagnosis. A high index of suspicion, leading to earlier diagnosis, is likely to reduce morbidity and mortality in this condition. In particular, change in gait is an indication for MRI. Spinal curvature or pain should prompt a full neurological examination and regular review. Change in continence occurs late, unlike constipation.

1 Stiller CA, Allen MB, Eatock EM. Childhood cancer in Britain: the national registry of childhood tumours and incidence rates 1978-1987. Eur f Cancer 1995;12:2028-34.

2 Anderson FM, Carson MJ. Spinal cord tumours in children: a review of the subject and presentation of twenty one a review of the subject and presen
cases. $\mathcal{F}$ Pediatr 1953;43:190-207.

3 Sutcliffe J. Torsion spasms and abnormal posturing in children with hiatus hernia: Sandifer's syndrome. Prog Pediatr Neurol 1969;2:190-7.

4 Blaser S, Harwood-Nash D. Pediatric spinal neoplasms. Topics MRI 1993;5:190-202.

5 Epstein FJ, Farmer JP. Pediatric spinal cord tumour surgery. Neurosurg Clin North Am 1990;1:569-90.

6 Dincer F, Dincer C, Baskaya MK. Results of the combined treatment of paediatric intraspinal tumours. Paraplegia 1992;30:718-28.

7 Steinbok P, Douglas Cochrane D, Poskitt K. Intramedullary spinal cord tumours in children. Pediatric Neuro-Oncolog 1992;3:931-44.

8 Hendrick EB. Spinal cord tumours in children. In: Youmanns JR. Neurological surgery. Philadelphia: WB Saunders, 1982:3215-22.

9 Reimer RR, Onofrio BM. Astrocytomas of the spinal cord in children and adolescents. $\mathcal{f}$ Neurosurg 1985;63:669-75.

10 Hardison HH, Packer RJ, Rorke LB, Schut L, Sutton LN, Bruce DA. Outcome of children with intramedullary spinal cord tumours. Child Nerv Syst 1987;3:89-92.

11 Matson DD, Tachdjian MO. Intraspinal tumours in infants and children. Review of 115 cases. Postgrad Med 1963;34: 279-85.

12 Cole G. Intraspinal tumours. Arch Dis Child 1988;63:1007-

13 Balague F, Nordin M. Backpain in children and teenagers. Baillieres Clin Rheumatol 1992;6:575-90.

14 Boriani S, Bigiani R, De Iure F, Andreoli I, Lari S, Di Fiore $M$. Low back pain in tumours. Chir Organi Mov 1994;79:93-9.

15 Carlioz H, Damsin JP. Torticollis in children. Ann Pediatr 1988;9:651-4.

16 McCormick PC, Torres R, Post DK, et al. Intramedullary ependymoma of the spinal cord. $\mathcal{F}$ Neurosurg 1990;72:52332 . 